\title{
Dynamics of the General Factor of Personality in Response to a Single Dose of Caffeine
}

\author{
Antonio Caselles ${ }^{1}$, Joan C. Micó ${ }^{2}$, and Salvador Amigó ${ }^{1}$ \\ ${ }^{1}$ Universitat de València (Spain) \\ ${ }^{2}$ Universitat Politècnica de València (Spain)
}

\begin{abstract}
General Factor of Personality $(G F P)$ research is an emergent field in personality research. This paper uses a theoretical mathematical model to predict the short-term effects of a dose of a stimulant drug on GFP and reports the results of an experiment showing how caffeine achieves this. This study considers the General Factor of Personality Questionnaire $(G F P Q)$ a good psychometric approach to assess GFP. The GFP dynamic mechanism of change is based on the Unique Trait Personality Theory (UTPT). This theory proposes the existence of GFP which occupies the apex of the hierarchy of personality, and extends from an impulsiveness-and-aggressiveness pole (approach tendency) to an anxiety-andintroversion pole (avoidance tendency). An experiment with 25 volunteers was performed. All the participants completed the GFPQ and the Sensation-Seeking Scale list of adjectives from the trait version of MAACL-R (Multiple Affect Adjective Checklist Revised) on an empty stomach. The participants in the experimental group (20) received $330 \mathrm{mg}$ of caffeine. All the participants filled in a state version form with the sensation-seeking adjectives every 4.5 minutes. This study considers that the Sensation-Seeking Scale list of adjectives from the $M A A C L-R$, available in both trait and state versions, is a good psychometric approach to assess GFP. The results show that GFP is modified by a single dose of caffeine in the direction predicted by the UTPT.
\end{abstract}

Keywords: general factor of personality, unique trait, sensation seeking, personality dynamic model, caffeine.

La investigación sobre el Factor General de Personalidad (FGP) es un campo emergente en la investigación sobre personalidad. Este artículo presenta un modelo matemático y teórico para predecir los efectos a corto plazo de una dosis de droga estimulante sobre el FGP y presenta los resultados de un experimento con café. El Cuestionario del Factor General de Personalidad (CFGP) es aquí considerado como una buena aproximación psicométrica para medir el FGP. Los mecanismos dinámicos de cambio del FGP están basados en la Teoría del Rasgo Único de Personalidad (TRUP). Esta teoría propone la existencia de un FGP que se sitúa en la cúspide de la estructura jerárquica de personalidad, y se extiende desde un polo de agresividad-impulsividad (tendencia de aproximación) hasta un polo de introversiónansiedad (tendencia de evitación). Se llevó a cabo un experimento con 25 voluntarios. Todos los participantes cumplimentaron en ayunas el Cuestionario del Factor General de Personalidad (CFGP) y la lista de adjetivos de búsqueda de sensaciones del MAACL-R en su versión de rasgo. Los participantes del grupo experimental (20) recibieron $330 \mathrm{mg}$ de cafeína. Todos los participantes cumplimentaron un cuestionario con los adjetivos de búsqueda de sensaciones, en su versión de estado, cada 4.5 minutos. En este estudio se considera que la escala de adjetivos de búsqueda de sensaciones del MAACL-R, tanto en versión rasgo como estado, es una buena aproximación psicométrica del FGP. Los resultados muestran que una dosis de cafeína modifica el FGP en la dirección predicha por la Teoría del Rasgo Único de Personalidad. Palabras clave: factor general de personalidad, rasgo único, búsqueda de sensaciones, modelo dinámico de personalidad, cafeína.

The analysis of the caffeine concentration in the coffee used in this experiment was performed in the Department of Analytical Chemistry, Universidad de Valencia, Spain.

Correspondence concerning this article should be addressed to: Antonio Caselles. Departament de Matemàtica Aplicada. Universitat de València. Dr. Moliner, 50, 46100 Burjassot. Valencia (Spain). E-mail: Antonio.Caselles@uv.es 
The following subsections will be considered in the Introduction: Caffeine and personality; The General Factor of Personality and the study of its modification; The proposed dynamic model; and The goals and objectives of this study.

\section{Caffeine and personality}

Caffeine is the most consumed drug in the world, with a history of 1400 years (Roberts \& Barone, 1983). Its potential misuse is lower than other legal drugs such as nicotine and alcohol (Nehlig, 1999). Nevertheless, the withdrawal effects it cause (Mitchell, De Wit, \& Zacny, 1995), and a relationship between dependence and reinforcing character measured in the laboratory (Garrett \& Griffiths, 1998; Tinley, Durlach, \& Yeomans, 2004; Yeomans, Spetch, \& Rogers, 1998), have been proved. In addition, craving and attention bias for caffeine-related stimuli have also been proved in the laboratory (Yeomans, Javaherian, Tovey, \& Stafford, 2005). This knowledge suffices to consider that studying the effect of caffeine consumption is a good approach to study the effect of other more addictive and dangerous misuse drugs.

On the other hand, there are some doubts in the literature about the causes of caffeine effects on efficiency and states of mind. It is unknown whether these causes are the absolute effect of caffeine or the alleviation of withdrawal effects (James, 1994; Rogers \& Dernoncourt, 1998). Both clear effects of caffeine and the effects that are partially due to the relief of recovering from withdrawal effects have been reported for vigilance tasks and reaction times for quite low doses, such as $30 \mathrm{mg}$ (Lieberman, Wurtman, Emde, Roberts, \& Coviella, 1987; Silverman \& Griffiths, 1992; Smit \& Rogers, 2000). Improvements on states of mind have also been obtained using scales such as "anxiety", "vigor", "arousal" and "positive mood" at medium and low doses, and with low frequency caffeine consumers (Childs \& de Wit, 2006; Haskell, Kennedy, Wesnes, \& Scholey, 2005; Nurminen, Niittynen, Korpela, \& Vapaatalo, 1999; Rogers, Martín, Smith, Heatherley, \& Smit, 2003; Smith \& Rogers, 2000; Warburton, Bersellini, \& Sweeney, 2001). However, this effect depends on dose and is lower than the effect produced by more addictive drugs such as damphetamine (Childs \& de Wit, 2006).

Besides considering doses, a greater increase in states of mind (greater response) of a group of habitual consumers with overnight caffeine abstinence has been found when compared with a group of low frequency consumers; however, no differences were found in the baseline (Yeomans et al., 2005). Nevertheless, there are inconsistencies in the literature regarding the differential effect in the baseline due to evidence of lower pre-treatment alertness ratings in high-dose $(355 \mathrm{mg})$ compared with low-dose $(100 \mathrm{mg})$ consumers (Rogers et al., 2003). Other positive effects have also been encountered, but only in certain groups (Swift
\& Tiplady, 1988) or situations, such as low arousal or being under the influence of depressive factors (Mackay, Tiplady, \& Scholey, 2002; Reyner \& Horne, 2000; Smith, Brice, Nash, Rich, \& Nutt, 2003).

It is very likely that many contradictory results for the differential reactivity to caffeine effects are the result of interactive effects among different factors, such as dose, hour of the day, level of habitual consumption and personality. A relationship between the conductance response of skin and extraversion has been observed in terms of caffeine doses (Smith, 1983). Effects of interaction among extraversion, hour of the day and caffeine have also been seen for both the impulsivity component (Revelle, Humphreys, Simon, \& Gilliland, 1980) and the sociability component (Wilson, 1990). In all cases, Eysenck's hypothesis (1967) is confirmed; that is, high levels of extraversion (with low basal levels of arousal) predispose to a higher reaction to caffeine. This is clearly observed in the mornings when extraverts, compared to introverts, present lower levels of arousal. In the afternoons, the tendency is inverted because transmarginal inhibition in extraverts (with greater arousal than in the mornings) diminishes their reaction to caffeine. The need of a mathematical connection among all the aforementioned factors is revealed.

Traditionally, factor analysis has been used to determine the components influencing the effect of caffeine and the interactions among them; however, studies about the dynamics of such an effect are lacking. Thus, the present study attempts to bridge this gap. A dynamic model which, from the General Systems Theory, analyzes the interaction among the different factors intervening in the effect of caffeine is proposed. Such factors include personality variables and caffeine variables. The model helps determine the changes of personality over time as a result of a single caffeine intake by starting from different personality characteristics. Thus, this study attempts to introduce an innovative methodology into the analysis of experiments on interactions between drug variables and personality variables.

\section{The General Factor of Personality and the study of its modification}

Firstly, we wished to determine the changes of whole personality in response to a single caffeine dose. The whole personality measure is currently known as the General Factor of Personality $(G F P)$.

Recently, GFP research has been revealed as an emergent field in personality research. It deals with "the single general factor hypothesis" and proposes a general factor of personality (within the five-factor model, or other personality models), which would occupy the apex of the hierarchy of personality factors (Erdle, Irwing, Rushton, \& Park, 2010; Musek, 2007; Rushton, Bons, \& Hur, 2008; Rushton \& Irwing, 2008; Rushton \& Irwing, 2009a, b, c, d; Schermer 
\& Vernon, 2010; Veselka et al., 2009a; Veselka, Schermer, Petrides, \& Vernon, 2009b).

A psychometric approach to assess the GFP has been proposed from the Life History Theory to obtain the KFactor (Bogaert \& Rusthon, 1989; Figueredo et al., 2006). The General Factor of Personality Questionnaire (GFPQ) (Amigó, Caselles, \& Micó, 2010) is presented as the first questionnaire that has been constructed expressly to measure the GFP.

There is evidence of the heritability of the general factor of personality. Studies with twins show that GFP has an early-age onset, with $50 \%$ of the variance attributable to a non additive (dominance) genetic influence and $50 \%$ to a unique, non shared environmental influence (Figueredo \& Rushton, 2009, Rushton, Bons, \& Hur, 2008; Veselka et al., 2009b).

A mathematical model of the GFP dynamics based on the General Systems Theory and the Unique Personality Trait Theory (Amigó, Caselles, \& Micó, 2008a; Caselles, Micó, \& Amigó, 2010) appears in the literature, but it has not been tested empirically to date. This article presents a first approach to the experimental verification of such a mathematical model. The Unique Personality Trait Theory (UPTT) (Amigó, 2005) proposes a hierarchical model where the highest level corresponds to the GFP, which extends from an impulsiveness-and-aggressiveness pole (approach tendency) to an anxiety-and-introversion pole (avoidance tendency). This continuum represents a wide personality dimension named extraversion (Amigó, 2005; Amigó et al., 2008a; Amigó et al., 2010; Caselles et al., 2010). In this case, extraversion has a broader meaning than that generally implied in current personality research, and was considered a cluster of second-order traits, similarly to $P$ ImpUSS (Psychoticism-Impulsive Unsocialised Sensation Seeking; Zuckerman, 1992; Zuckerman, Kuhlman, Joireman, Teta, \& Kraft, 1993), or the ImpASS (Impulsive Antisocial Sensation Seeking) Trait Cluster (Pickering, 2004) or a group of Behavioral Activation System-related traits $(B A S$ related traits) (Pickering \& Smille, 2008). Thus we consider extraversion, as defined above, to be the physiological substrate of the GFP, and the UPTT as the explanatory model of the physiological mechanisms of this trait. In this sense, this paper considers GFP and extraversion to be broadly synonymous concepts.

In the UPTT context, the tonic activation level (or basal activation level, which is the genetic activation level that arises in the organism in a resting state) is distinguished from the phasic activation level (which arises as a response to a particular stimulus, such as drug intake). On shortterm time scales (typical of the acute effect of a stimulant drug), high extraverts display lower tonic activation levels and higher phasic activation levels than low extraverts, whose tonic activation level and phasic activation level are higher and lower, respectively (Amigó, 2005; Amigó et al, 2008a; Caselles et al., 2010).
What all this shows is that Rushton's and our views of GFP are similar but not the same. Rushton et al. (2008, 2009) consider that the positive and negative poles of the $G F P$ are well-defined and that individuals with high GFP possess more cooperative and pro-social personalities. Therefore, the GFP would result from a natural selection for socially desirable behavior. The UPTT (Amigó, 2005) does not predict that all the traits included in the GFP are "desirable". This theory predicts that the GFP is related with social deviance traits. For example, positive and significant correlations have been obtained between the GFP and antisocial disorder of personality (Amigó et al., 2010). Moreover, Rushton's work is based on the description of the relationships between different personality traits and a GFP extracted from different personality scales. We work with a questionnaire that has been specifically devised to assess the GFP (the GPPQ; Amigó et al., 2010), which is of interest to study the psychological and physiological mechanisms of the GFP and its changes.

Finally, a dynamic model with an individual-centered methodology is applied in this paper. It allows a better understanding of the mutual influence of personality and the effect of stimulant drugs. To go about this, we used the Sensation-Seeking Scale, composed of 12 adjectives selected from the original Multiple Affect Adjective Check List $(M A A C L-R)$ by Zuckerman and Lubin (1985). A score from both the trait and state versions has been obtained. This scores relates more to $E$ than to $P$, and represents factors such as surgency or vigor and, in its trait version, it correlates moderately with the established measures of a sensationseeking trait (Lubin, Van Whitlock, Reddy, \& Petren, 2001). As other papers have previously discussed (Amigó et al., 2008a; Amigó et al., 2010), the sensation-seeking trait strongly relates with the GFP. As previously mentioned, the extraversion trait is similar to the Impulsive Antisocial Sensation-Seeking Trait Cluster. So, the trait/state format of sensation seeking will be considered in this paper, as in others (Caselles et al., 2010), to be a good approach for the trait/state GFP which must be developed in the future. Moreover, several combinations of the adjectives from this scale have been found to highly relate with the GFP (Amigó, Micó, \& Caselles, 2008b). In addition, they are a good measure of the GFP in its state format (Amigó, Micó, \& Caselles, 2009).

Thus, there is a trait format and a state format for this list of adjectives. The "personality states" version allows an assessment of personality at each time instant in terms of a determined stimulus, such as caffeine. This assessment is similar to that performed by states-of-mind or situationeffect scales created mainly for this purpose, such as the Profile of Mood States (POMS, McNair \& Droppleman, 1971). The theoretical foundation of this purpose is supported by the hierarchical personality models, particularly Pelechano's parameters model $(1973,2000)$, which considers three consolidation levels of personality dimensions, from the highest level of consolidation to the situational or state- 
level one. For instance, this model considers a transitory state of anxiety as an aspect of personality, but one that is more reactive when faced with influences of the context than the anxiety trait, which is more consolidated.

Moreover, Schutte, Malouff, Segrera, Wolf, and Rodgers, (2003) devised a Big Five States Inventory which started from the hierarchical model of personality. Traits are conceptualized as higher-level, enduring characteristics, while states are lower-level, less enduring characteristics (p. 592). They used a confirmatory factor analysis $(C F A)$ that provided an acceptable fitting degree between responses on measurements of transitory states and the Big Five dimensions. Subjects had to answer the following question: "Describe yourself as you see yourself at the present time, not as you wish to be in the future or as you were in the past" (p. 594). They used experimental manipulation and a positive mood induction procedure to attempt to change the levels of the Big Five States. A significant increase was noted in surgency, agreeableness and openness from pre- to post-induction.

This setup is based on having both trait and state measures of personality that arise from the same adjectives. It offers two advantages: 1) the isomorphism of the measures, which does not require different measure instruments to assess trait and state; 2) the possibility of studying in detail the dynamics of personality in the very short term using the same factors considered for the study of personality in the long term (stable personality). In short, the research design herein presented focuses on the study of intra-individual variability and the dynamics of personality in the very short term, and in relation to stable personality.

\section{The proposed dynamic model}

We now go on to present the dynamic model used in this study.

Let $y(t)$ be the extraversion variable. The model chosen to compute the dynamics of this variable, as a result of a stimulus produced by a stimulant drug intake, is that introduced by Amigó et al., (2008a). Therefore, $y(t)$ is the extraversion variable (measured on the hedonic scale), considered the "unique personality trait" (General Factor of Personality), whose biological base is the general activation level. We hypothesize that the sensation-seeking variable herein considered can be identified with the extraversion variable considered (see Sections 1.1 and 1.2). The differential equation that states the model is:

$$
\begin{aligned}
& \frac{d y(t)}{d t}=\left\{\begin{array}{l}
a(b-y(t))+\frac{p}{b} s(t): \quad 0 \leq t \leq \tau \\
a(b-y(t))+\frac{p}{b} s(t)-b \cdot q \cdot s(t-\tau) \cdot y(t-\tau): \quad t>\tau
\end{array}\right\} \\
& y(0)=y_{0}
\end{aligned}
$$

where the meaning of the symbols is the following:

$$
\begin{array}{ll}
t: & \text { time. } \\
y(t): & \text { extraversion or activation level. } \\
s(t): & \text { caffeine in blood. } \\
a: & \text { power of the homeostatic effect. } \\
b: & \text { steady-state value (genetic value) of } y(t) . \\
p: & \text { power of the excitation effect. } \\
q: \quad \text { power of the inhibition effect. } \\
\alpha: \quad \text { distribution rate of caffeine in blood. } \\
\beta: \quad \text { elimination rate of caffeine from the organism. } \\
\tau: \quad \text { delay of the inhibition effect (it arises after the } \\
\left.y_{0}: \quad \text { initial extraversion value (normally } y_{0}=b\right) .
\end{array}
$$

The variables and parameters included in this equation are summarized in Table 1, along with their measure units. Equation (1) states that the variation of $y(t)$ has three components: the homeostatic effect $a \cdot(b-y(t))$, the excitation effect $p \cdot s(t) / b$ and the inhibition effect $b \cdot q$. $s(t-\tau) \cdot y(t-\tau)$. The reasons that justify the form this equation takes are explained in the paper of Amigó et al. (2008a); nevertheless some details are provided below in order to make the paper self-contained.

Table 1

Dynamic model variables and their respective measurement units

\begin{tabular}{ccc}
\hline Variable & Symbol & Units \\
\hline Dose & $M$ & milligrams $(\mathrm{mg})$ \\
minutes $(\mathrm{min})$ & $(\mathrm{mg} / \mathrm{min}) / \mathrm{mg}$ \\
Inhibitor effect delay & $\tau$ & $(\mathrm{mg} / \mathrm{min}) / \mathrm{mg}$ \\
Distribution rate & $\alpha$ & Sensation-Seeking Scale units $(\mathrm{sss})$ \\
Tonic or basal extraversion (trait) & $\boldsymbol{s s s}$ \\
Initial extraversion (initial state) & $y_{0}$ & $(\mathrm{sss} / \mathrm{min}) / \mathrm{sss}$ \\
Homeostatic control rate & $a$ & $(\mathrm{sss} / \mathrm{min}) \cdot(\mathrm{sss} / \mathrm{mg})$ \\
Excitation effect power & $p$ & $1 /(\mathrm{sss} \cdot \mathrm{mg})$ \\
Inhibitor effect power & $q$ & $\mathrm{mg}$ \\
Initial drug in blood & $\mathrm{s}_{0}$ & $\mathrm{sss}$ \\
Extraversion (phasic) & $y(t)$ & $\mathrm{mg}$
\end{tabular}


Equation (1) is a delay differential equation, with delay $\tau$ (called inhibition effect delay) and initial condition $y_{0}$. Therefore under the stated hypothesis, this variable theoretically measures the state sensation-seeking level (SS$S$ registers) versus time as a result of caffeine intake. Thus, $y_{0}$ represents the $S S-S$ register before coffee is consumed.

The homeostatic control flow $B(t)=a(b-y(t))$ and the excitation effect flow $E(t)=p / b s(t)$ are computed before and after the delay, while the inhibitor effect flow $D(t)=b$ $\cdot q \cdot s(t-\tau) \cdot y(t-\tau)$ is only computed after the delay. In all three flows, $b$ is the tonic or basal activation level; that is, the stable trait of the sensation-seeking variable, which is genetic in nature (is specific for each individual) and, a priori, its value is unknown. From a mathematical viewpoint, it is a steady state, thus all the trajectories asymptotically tend to the $b$ value. The other parameters are: the homeostatic control rate $a$, the excitation effect power $p$ and the inhibitor effect power $q$. All the parameters depend on the individual's biology.

On the other hand, $s(t)$ is the stimulus-variable that represents the amount of drug (caffeine) in blood at each time instant. Its functional dependence on time is:

$$
s(t)=\left\{\begin{array}{l}
\frac{\alpha \cdot M}{\beta-\alpha}(\exp (-\alpha \cdot t)-\exp (-\beta \cdot t)): \quad \beta \neq \alpha \\
\alpha \cdot M \cdot t \cdot \exp (-\alpha \cdot t): \quad \beta=\alpha
\end{array}\right.
$$

Equation (2) is obtained as the solution of two coupled differential equations (see Amigó et al., 2008a). $M$ is the dose of the drug intake, $\alpha$ is the distribution rate and $\beta$ is the elimination rate. Both $\alpha$ and $\beta$ also depend on the individual's biology.

Differential Equation (1) has an analytical solution, which is used herein. This outcome permits us to explicitly compute the evolution of both the sensation-seeking variable $y(t)$ versus time and the excitation-inhibitor balance versus time. This balance variable allows us to theoretically validate the model because its dynamics coincides not only with what the opponent-process theory by Solomon and Corbit (1974) proposed and predicted to explain the acute effect of drugs, but also with the model proposed by S. Grossberg (2000), which predicts a similar time pattern for $X(t)$.

In the present experiment, the dose unit is one milligram and the time unit is one minute. The most important variable is the extraversion variable $y(t)$. In the work of Amigó et al. (2008a), the extraversion unit is the theoretical hedonic scale unit, which was also used by Solomon and Corbit (1974) and by S. Grossberg (2000) for the same variable to theoretically quantify the effect of a stimulant drug on an individual. Nevertheless, if a model like the one presented herein has to be verified, the representative variable must be observable; that is, it can be reproduced in an experiment. Following this idea, the extraversion variable in the present work has been measured by the Sensation-Seeking Scale from the MAACL-R using the SS-S scores, whose range of variation is $[0,60]$. The reason why extraversion can be interpreted as sensation seeking has been explained above; this is because the representative variable $y(t)$ in this context is presented as the sensation-seeking variable.

\section{The goals and objectives of this study}

The main goal of this study is to obtain evidence of the possibility of modifying the GFP in the laboratory. With this aim in mind, an experiment has been designed and performed in an attempt to determine the short-term effect (1.5 hours) of one caffeine dose on the GFP measured at 4.5-minute intervals with the Sensation-Seeking Scale list of 12 adjectives selected from the MAACL-R of Zuckerman and Lubin (1985), which is considered a good psychometric approach to the GFP in the state format.

Thus, the first objective of the study is the experimental determination in each participant of the personality variations produced in the laboratory.

The second objective is to experimentally verify a published mathematical model (Amigó et al., 2008a) which covers the dynamics of extraversion (considered herein to be the physiological basis of the $G F P$ ) as a response to a single drug intake. Such a model was obtained using the General Systems Theory conceptual framework, with which this study clearly addresses a systemic, global and complex conception of personality.

The third and final objective is to analyze the response mechanism of extraversion (GFP) to a stimulant drug intake. The UPTT (Amigó, 2005) (which attempts to study the action mechanisms of extraversion or GFP) proposes that high extraverts will present higher phasic reactions to a caffeine dose than low extraverts. The experimental verification of this proposition would contribute to the verification of this theory.

To summarize, these are very diverse, broad objectives, but necessary ones to undertake an in-depth study into the complex relationship between the individual as a whole (personality) and the environment (reaction to a drug intake, in this case).

\section{Methods}

The participants, instruments and procedure will be considered in this section.

\section{Participants}

Twenty-five adults participated in the experiment. They were university students and professors; 14 males; 11 females. The mean age was 30.13 with ages ranging between 21 and 61 years. Participants were divided into two groups: the experimental group ( $E G, n=20$, namely Case 1 to Case $20)$, and the control group ( $C G, n=5$, namely Control 1 to Control 5). 


\section{Instruments}

1. General Factor of Personality Questionnaire (GFPQ) (Amigó et al, 2010). The GFPQ is a 20 Likert response item questionnaire containing two scales with 10 items each: 1) the Extraversion Scale (ES) and the Introversion Scale $(I S)$. A total score can be obtained by adding both scores from these subscales. This total score will be that used in this study.

2. List of adjectives from the Sensation-Seeking Scale $(S S)$, selected from the Multiple Affect Adjective Checklist Revised (MAACL-R; Zuckerman \& Lubin, 1985). The 132-item $M A A C L-R$ provides valid measures of anxiety, depression, hostility, positive affect and sensation seeking. SS is a 12 Likert response item scale. Its adjectives are: active, adventurous, aggressive, daring, energetic, enthusiastic, merry, mild, quiet, tame, wild and bored. Two versions were used for the list of adjectives from the SensationSeeking Scale: trait format (SS-T) ("Are you like this in general?") and state format (SS-S) ("Are you like this at this moment?" or "do you feel so at this moment?"). This scale is used in this study because it is a good approach to the GFP.

\section{Procedure}

All the participants were requested to refrain from consuming caffeine since the afternoon prior to the experiment, which they did on an empty stomach. A group of five individuals participated in each experiment. Once they were all together in the room where the experiment was to take place, they filled in the $G F P Q$ and two forms with the two lists of adjectives from the $M A A C L-R$ in its trait and state formats. Next, they had two cups of coffee, a total amount of $330 \mathrm{mg}$ of caffeine ( $280 \mathrm{cc}$ of coffee with a concentration of: $1172 \pm 15 \mathrm{mg}$ / liter). From this time, and for 1.5 hours, they filled in a form with the list of adjectives from the state $M A A C L-R$ version every 4.5 minutes, until a total of 20 registers was obtained. This method permits a short-term register (1.5 hours) variation of the individual's personality. Note that the referred adjectives in the state format represent situational aspects of personality.

In order to obtain previous experiences (adequate time intervals and instructions for subjects, best general procedure, etc.), a pilot study (not reported in this paper) with other participants was performed; which is the reason for defining an experiment lasting 1.5 hours. The previous pilot experimental design with several types of individuals has demonstrated that, after this time, participants show evidence of boredom that affected the objectivity of the scores. With 4.5-minute intervals between the administrations of forms, participants had enough time to fill in the form, to observe each other, and to even wait (a longer time would lead to loss of concentration).
The previous pilot experiment is also useful to state that the control participants show considerable tiredness and lack of motivation after 1.5 hours from the beginning of the experiment (there were several withdrawals). These circumstances led to center attention on the experimental participants (those consuming coffee) and to restrict the control group to five participants. After observing the results of the proposed experiment (set out below), it has been confirmed that five control participants offer enough adequate information for the purposes of this study.

The placebo effect has not been considered in this study design because the purpose of this study was neither to distinguish the effect of coffee from the effect of other variables (such as suggestion, type of instructions, hour of the day, or mood) nor to prove that coffee has a stimulant effect (which is well-known). Indeed, the Introduction of this paper cites lots of experimental results along these lines. The interest of the experiment centers on the study of the short-term dynamic change of personality, which is measured from a list of adjectives and produced by ingesting a substance with well-known stimulant effects, such as caffeine. This study is based on the General Systems Theory and may be improved in the future by considering more variables and many other experimental conditions.

\section{Results}

Two forms of results are presented: statistical ones and those corresponding to the verification of the dynamic model.

\section{Statistical results}

Several types of scores were obtained:

1. The General Factor of Personality Questionnaire score.

2. The MAACL-R scores in their trait and state versions ( $S S-T$ and $S S-S$, respectively).

3. The Differential Score $(D I F)$ between $S S-T$ and $S S$ $S$ (only from the experimental group). SS-T and $S S$ $S$ are measured at the beginning of the experiment, before the first coffee intake. Following the Unique Personality Trait Theory, the greater the difference is, the greater the phasic reaction to coffee will be. That is because the participant is able to reach a high level in the seeking-sensations trait (SS-T) when is infra-stimulated at the beginning of the experiment $(S S-S)$.

4. The Maximal Score $(M A X)$ obtained at $S S-S$ after the coffee intake (only from the experimental group). It represents the maximum level reached by $S S-S$ as an effect of coffee.

No significant differences were found between the experimental group $(n=20)$ and the control group $(n=5)$ in both the $S S-T$ and $S S-S$ using the Mann-Whitney $U$ test 
for independent samples. Thus, the causes of the observed effects in Cases 1 to 20 in the $S S-S$ scores were a result of coffee intake.

The relationship between GFPQ and the SS-T is positive and significant $(r=.53 ; p<.01)$. So, we accept that the trait sensation-seeking scores, measured with the $S S$ - $T$, are a good approach to the GFP. Furthermore, we tentatively accept that the state sensation-seeking scores, measured with the $S S-S$, are a good approach to the GFP in its state version.

An interesting result arose from the experimental group regarding the Differential Score $(D I F)$. First, we obtained the median of the variable SS-T to form two groups (35), one with high scores and one with low scores (above and below the median). Next, and given that the study samples were small, we used a nonparametric test (Mann-Whitney $U$ test) for two independent samples to compare scores: the subgroup with an $S S-T$ score over $35(n=11)$ and the subgroup with an $S S-T$ score under $35(n=9)$, which presented a significant difference $(U=16.5 ; p<.05)$. The interpretation of this outcome is the following: the difference between the trait level and the state level for high sensation seekers, before drinking coffee, is significantly higher than the same difference found for low sensation seekers. That is, those participants with a high level in the sensationseeking trait are infra-stimulated early in the morning, after getting up and before drinking coffee, and when there is no stimulus to excite them. Conversely, those participants with a low level in the sensation-seeking trait have a level of stimulation in the morning and before drinking coffee that is very close to their corresponding trait level. All these results are congruent with the UPTT presented in the Introduction.

In addition, a significant positive correlation was found after coffee intake between $D I F$ and $\operatorname{MAX}(r=.57 ; p<$ $.01)$. That is, the greater the difference between the $S S-T$ and the $S S-S$, the greater the maximum obtained score after coffee intake (MAX). The UPTT predicts that high sensation seekers (with a significant difference between the $S S$ - $T$ and the $S S-S$ ) would present a higher phasic response to a stimulant than low sensation seekers, which is precisely what the results reveal.

It is important to insist on these last results. High sensation seekers, before coffee intake, present a lower state level under low stimulation conditions; however, the greater the difference between the $S S$ - $T$ and the $S S-S$, the greater the score after coffee intake. It is also necessary to remember that the $S S-T$ in this article has been confirmed to be a good approach to the GFP (trait), and that the SS$S$ is tentatively considered to be a good approach to the GFP (state).

The next section confirms and completes these consequences with a mathematical model and, at the same time, contributes to experimentally verify the models of Amigó et al. (2008a) and of Caselles et al. (2010).

\section{Verification of the dynamic model}

The aim of this section is to verify Model (1) through the data obtained from the lists of the $S S$-S scores provided by the experimental subjects based on the adjectives, both before caffeine intake ( $y_{0}$ value) and after caffeine intake, and every 4.5 minutes $(y(t)$ values).

The expected curve to represent the evolution of the activation level over time is an inverted $U$ that perhaps ends with one or more oscillations around the equilibrium value (See Amigó et al., 2008a). It is well-known that the effect of caffeine can be prolonged for more than 1.5 hours; consequently, we expect inverted $U$ patterns and, exceptionally, a complete inverted $U$ with some oscillations at the end.

The verification process includes the three following phases:

Phase 1: fitting the parameters by trial and error. A trialerror route to fit the model to the real data, and which considers the mathematical role of the parameters $(a, b, p$, $q, \tau, \alpha, \beta)$ in the overall model context has been performed. In this phase, the fitting criterion is the visual inspection of the evolution curve predicted by the model, represented in the same diagram as the real values corresponding to the Sensation-Seeking Scale (see Figures 1 to 20). The interpretation of the parameters is as follows:

- $a$ : Homeostatic control rate. It indicates the speed of the approach of the activation level $y(t)$ to the tonic activation level $b$. An increase in its value lowers the total summit of the model curve, and vice versa.

- $b$ : Tonic or basal activation level. As a first approach, the $b$ value has been considered to coincide with the observed tendency of activation when the experiment ends.

- $p$ : Excitation effect power. It indicates the relative strength of the caffeine effects in relation to other possible drugs. An increase in its value is the equivalent to an increase in the total summit of model curve, and vice versa.

- $q$ : Inhibitor effect power. It indicates the relative strength of stopping the effects of caffeine. An increase in its value diminishes the final right-hand slope of the model curve after the delay time, and vice versa.

- $\alpha$ : Distribution rate. It indicates the speed of distribution of caffeine in blood inside the digestive system. On the one hand, its increase increments the left-hand slope of the model curve before the maximum, and vice versa. On the other hand, an increase in its value is the equivalent to an increase of the total height of the model curve, and vice versa.

- $\beta$ : Elimination rate. It indicates the speed of caffeine disappearing from blood, its absorption by cells or its elimination through urine. On the one hand, its 
increase diminishes the right-hand slope of the model curve after the maximum, and vice versa. In addition, when $\beta \neq \alpha$ an increase in the $\beta-\alpha$ value decreases the total height of the model curve and vice versa.

- $\tau$ : Delay of the inhibition effect. It indicates the time when the inhibitor effect occurs. Its first value has been chosen by visually inspecting diagrams and by a trial-and-error process.

- $M$ : Dose of caffeine. In the experiment, it was 330 $m g$ (280 cc of black coffee with a concentration of $1172 \pm 15 \mathrm{mg} /$ liter $)$. An increase in this dose would represent an increase of the excitation and inhibitor effects, and vice versa.

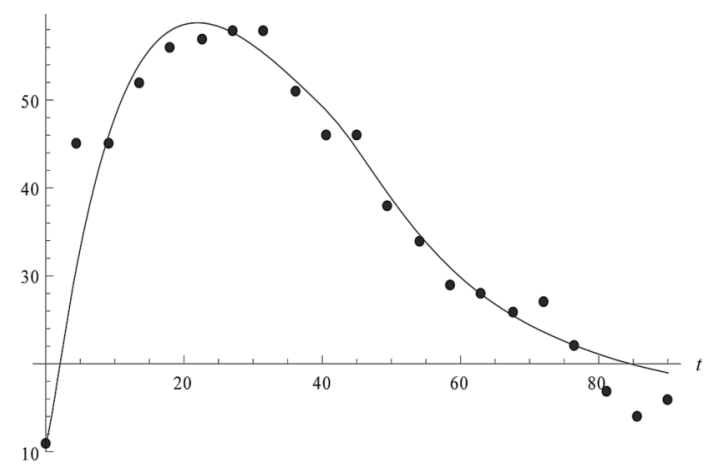

Figure 1: Case 1 (experimental group), real values $x(t)$ (dots) together with model values $y(t)$ (line) versus time $t$.

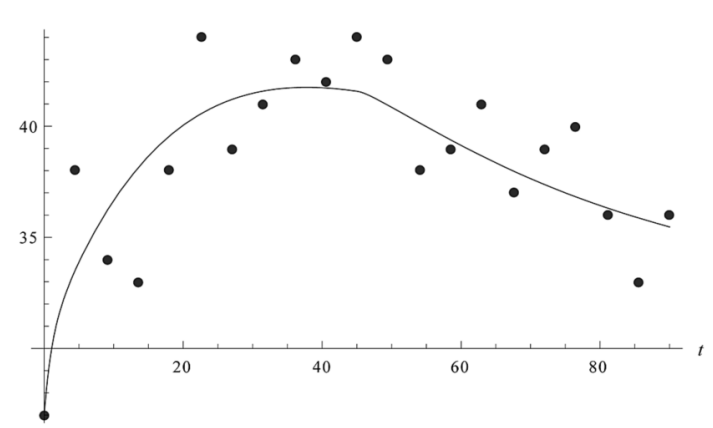

Figure 2: Case 2 (experimental group), real values $x(t)$ (dots) together with model values $y(t)$ (line) versus time $t$.

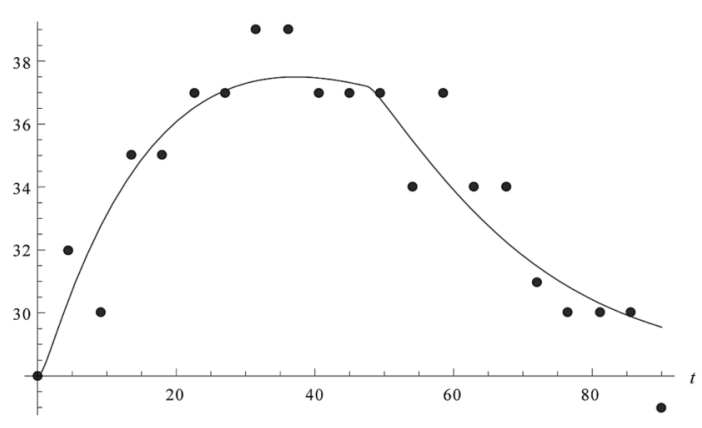

Figure 3: Case 3 (experimental group), real values $x(t)$ (dots) together with model values $y(t)$ (line) versus time $t$.

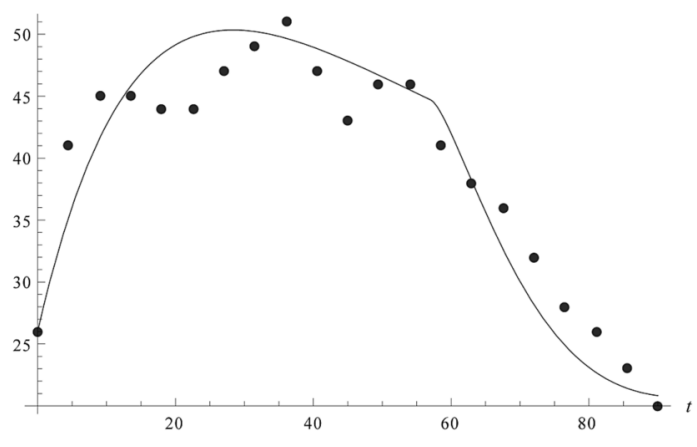

Figure 4: Case 4 (experimental group), real values $x(t)$ (dots) together with model values $y(t)$ (line) versus time $t$.

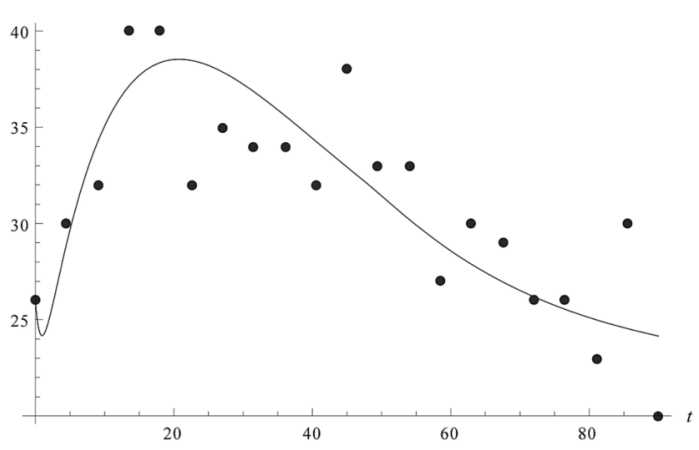

Figure 5: Case 5 (experimental group), real values $x(t)$ (dots) together with model values $y(t)$ (line) versus time $t$.

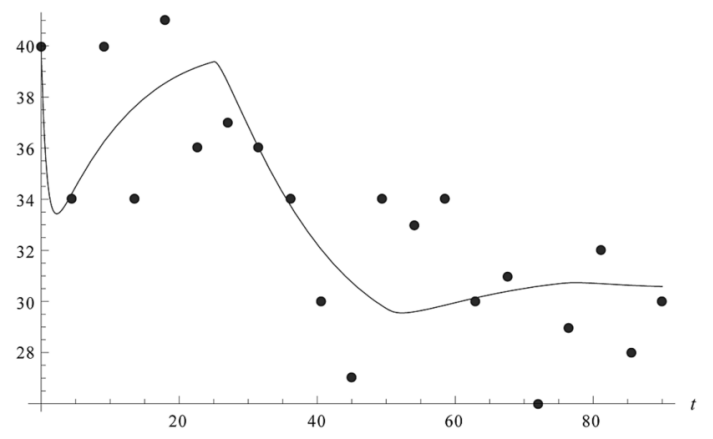

Figure 6: Case 6 (experimental group), real values $x(t)$ (dots) together with model values $y(t)$ (line) versus time $t$.

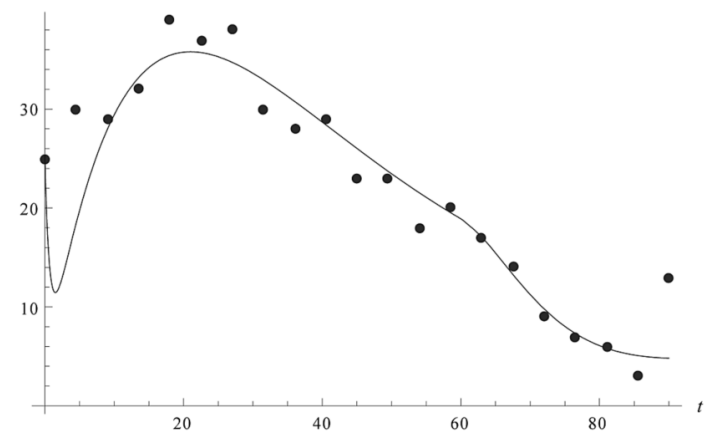

Figure 7: Case 7 (experimental group), real values $x(t)$ (dots) together with model values $y(t)$ (line) versus time $t$. 


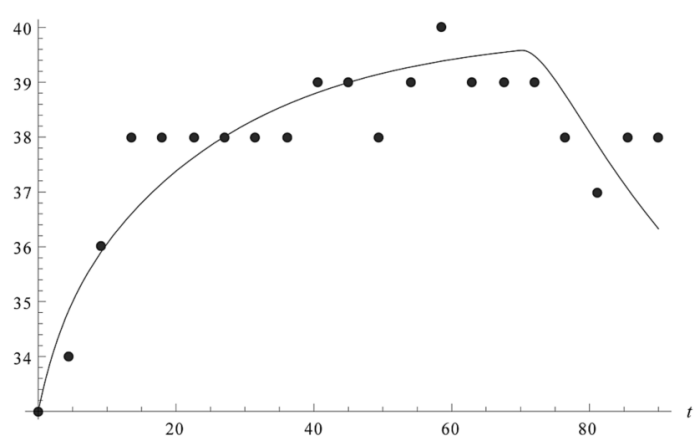

Figure 8: Case 8 (experimental group), real values $x(t)$ (dots) together with model values $y(t)$ (line) versus time $t$.

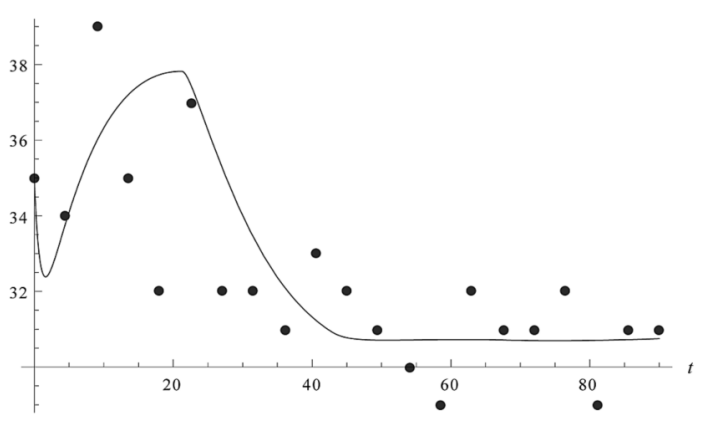

Figure 9: Case 9 (experimental group), real values $x(t)$ (dots) together with model values $y(t)$ (line) versus time $t$.

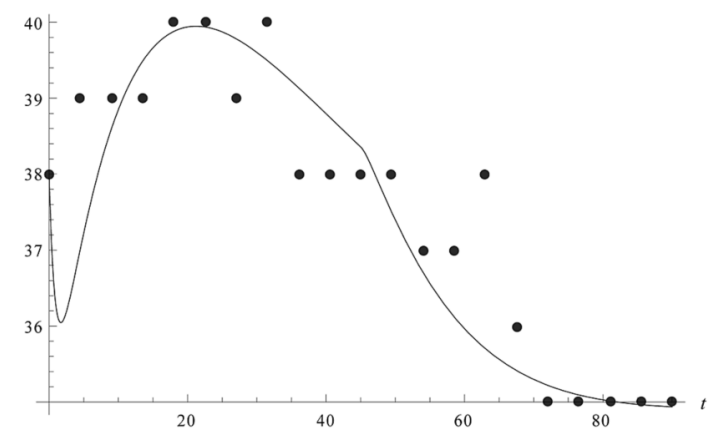

Figure 10: Case 10 (experimental group), real values $x(t)$ (dots) together with model values $y(t)$ (line) versus time $t$.

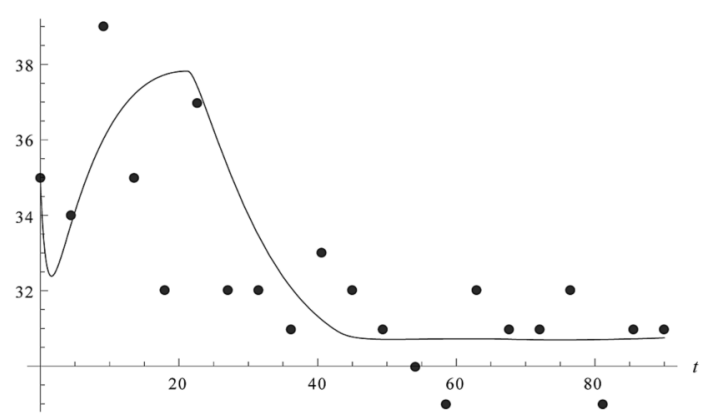

Figure 10: Case 10 (experimental group), real values $x(t)$ (dots) together with model values $y(t)$ (line) versus time $t$.

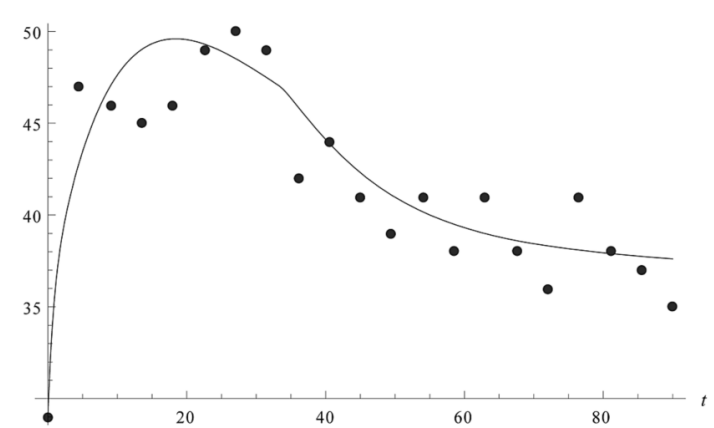

Figure 11: Case 11 (experimental group), real values $x(t)$ (dots) together with model values $y(t)$ (line) versus time $t$.

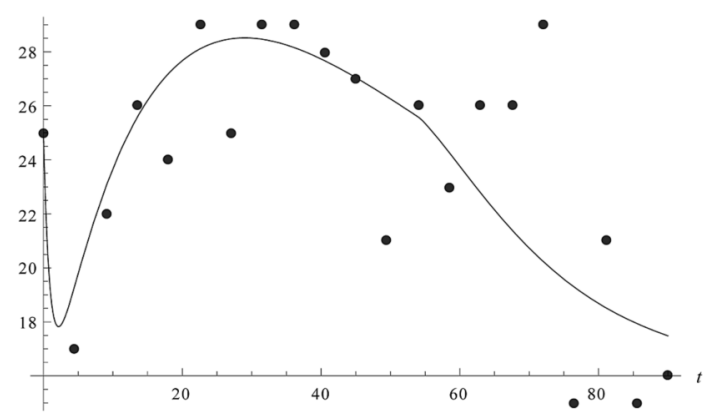

Figure 12: Case 12 (experimental group), real values $x(t)$ (dots) together with model values $y(t)$ (line) versus time $t$.

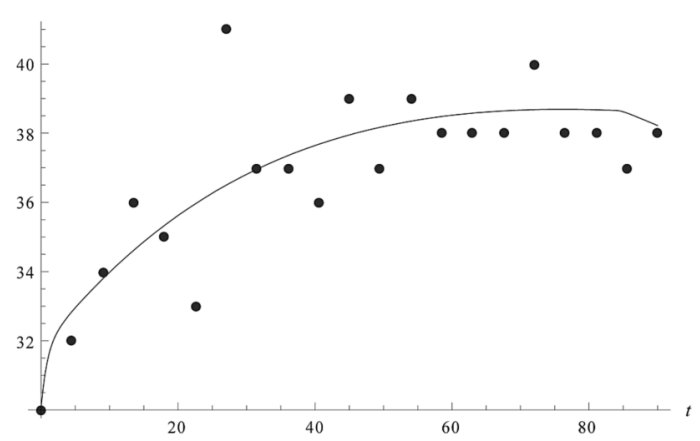

Figure 13: Case 13 (experimental group), real values $x(t)$ (dots) together with model values $y(t)$ (line) versus time $t$.

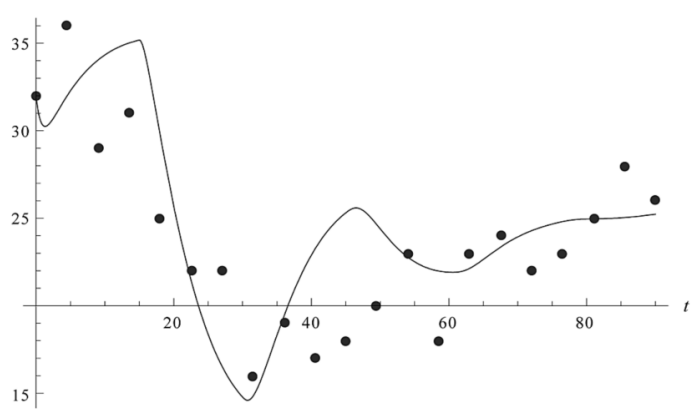

Figure 14: Case 14 (experimental group), real values $x(t)$ (dots) together with model values $y(t)$ (line) versus time $t$. 


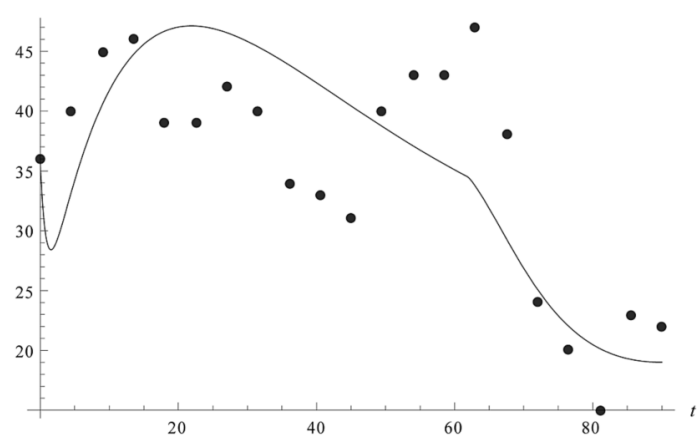

Figure 15: Case 15 (experimental group), real values $x(t)$ (dots) together with model values $y(t)$ (line) versus time $t$.

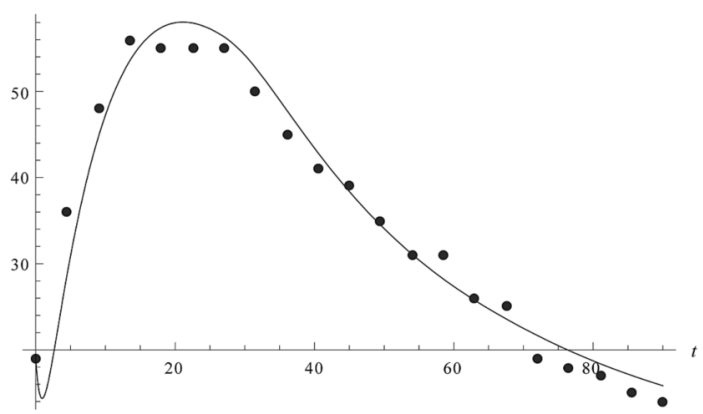

Figure 16: Case 16 (experimental group), real values $x(t)$ (dots) together with model values $y(t)$ (line) versus time $t$.

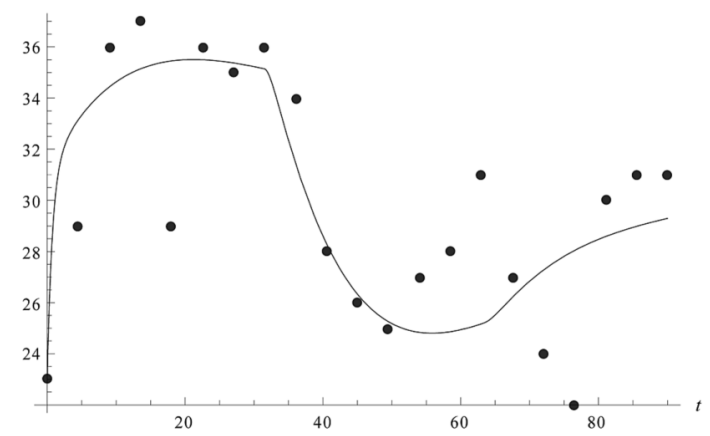

Figure 17: Case 17 (experimental group), real values $x(t)$ (dots) together with model values $y(t)$ (line) versus time $t$.

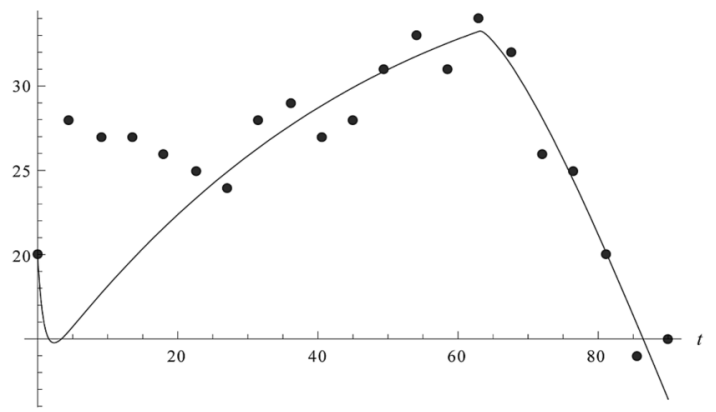

Figure 18: Case 18 (experimental group), real values $x(t)$ (dots) together with model values $y(t)$ (line) versus time $t$.

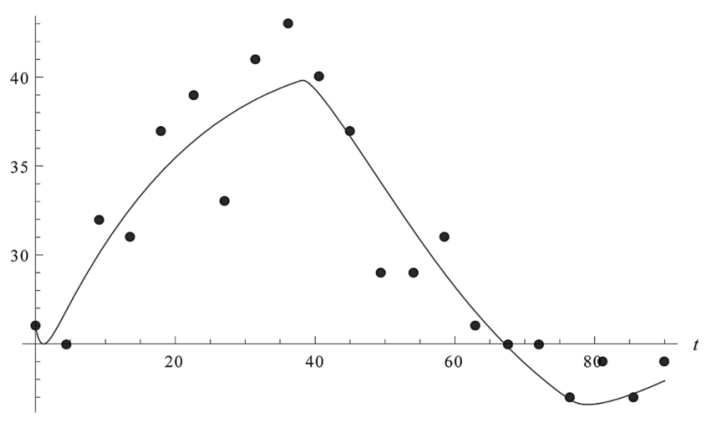

Figure 19: Case 19 (experimental group), real values $x(t)$ (dots) together with model values $y(t)$ (line) versus time $t$.

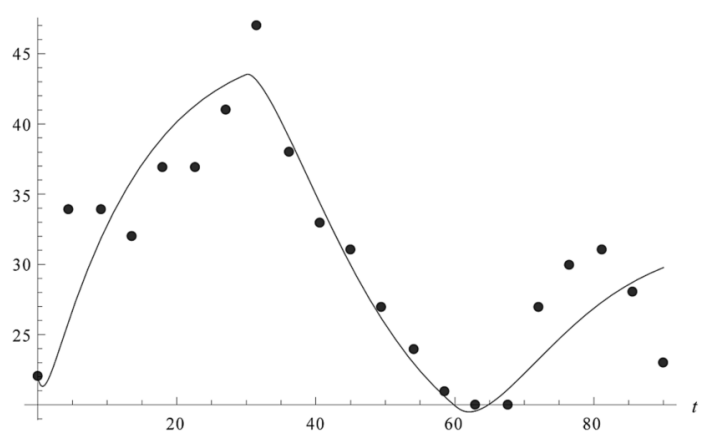

Figure 20: Case 20 (experimental group), real values $x(t)$ (dots) together with model values $y(t)$ (line) versus time $t$.

Phase 2: Refining the values of the model parameters obtained in Phase 1 by using an "ad hoc" computer program. A blind iteration process is possible (when omitting Phase 1 ), but it normally requires a longer computation time. The fitting criterion used by the program was the maximization of the determination coefficient $R^{2}$. This fitting program was inspired by the program of Caselles (1998) to fit complex functions to real data. In this phase, the determination coefficient $R^{2}$ was computed as a measure of the goodness-of-fit between the values corresponding to the model curve, given by the result of Equation (1), and the values corresponding to the Sensation-Seeking Scale (see Table 2). Thus, if $x_{i}$ represents the values of the Sensation-Seeking Scale, measured every 4.5 minutes then $y_{i}$ represents the values of the Sensation-Seeking Scale, provided by Model (1) every 4.5 minutes, and $x$ and $y$ depict the mean values, then $R^{2}$ is computed as:

$$
R^{2}=\frac{\left(\sum_{i=1}^{N}\left(x_{i}-\bar{x}\right)\left(y_{i}-\bar{y}\right)\right)^{2}}{\sum_{i=1}^{N}\left(x_{i}-\bar{x}\right)^{2} \sum_{i=1}^{N}\left(y_{i}-\bar{y}\right)^{2}}
$$


In other words, the determination coefficient $R^{2}$ computes the square of the covariance divided by the product of the variances. The $R^{2}$ values are between zero and one. The closer the values of $R^{2}$ are to one, the better the model explains the variability of the real data. $R^{2}$ represents the fraction of the uncertainty of data explained by the fitted model (for instance, see Draper \& Smith, 1981) and is, consequently, an adequate method to estimate the goodnessof-fit for the case.

Phase 3: An analysis of the model residuals is done to check both the normal distribution hypothesis and the homoscedasticity hypothesis (the variance of the residuals does not depend on the values of the independent variable). The first is assessed with the Kolmogorov-Smirnov test, and the second by the visual inspection of the residuals versus both the computed values and the independent variable (time). The analysis of the model residuals is important for correctly interpreting the high dispersion of the measures as really being noise and not as a defect of fitting. In other words, while $R^{2}$ informs us about the deterministic interpretation of the evolution of the Sensation-Seeking Scale data, the confirmation of the hypotheses for the residuals informs us about the random nature of the differences between the computed values and the real values; this fact is essential to accept the model as a well-fitting one (for instance, see Draper \& Smith (1981). A feed-back process among Phases 1,2 and 3 will be necessary to obtain a fitting curve where the two normality and homoscedasticity hypotheses of the results hold, therefore the residuals can be considered to be noise. In our experiment, this process produced the results provided in Table 2 for the experimental group.

In the second column of Table 2, the determination coefficient $R^{2}$ for Cases 1 to 20 varies between 0.485529 (Case 2) and 0.967700 (Case 16), which represents a high fitting degree between the real data and the theoretical curve given by (1). Figures 1 to 20 show the plots of the experimental results of extraversion $(G F P)$ (measured by the Sensation-Seeking Scale) together with the theoretical curve (the extraversion values $(G F P)$ calculated by the model) for Cases 1 to 20. In general, a good fit between the experimental values and the theoretical curve can also be observed visually.

The Kolmogorov-Smirnov test results for the residual variable are presented in the third column of Table 2. They are small enough to consider that this variable is normally distributed. In addition, the residual variable plots versus both the computed values and the independent variable (time) indicate that the homoscedasticity hypothesis holds; namely, that the residuals depend on neither the computed values nor the independent variable (time). The conclusion is that the residuals may be considered random; that is, the variability of the extraversion variable (the GFP approach by the $S S-S$ ) has been correctly explained by Model (1) at the present description level. This random nature of the residuals would be typical of a variable such as extraversion $(G F P)$ (measured with the Sensation-Seeking Scale) which

Table 2

Determination coefficient and Kolmogorov-Smirnov test for the residuals corresponding to the cases in the experimental group

\begin{tabular}{lcc}
\hline & Determination coefficient & Kolmogorov-Smirnov test \\
\hline CASE 1 & 0.930624 & 0.2272860 \\
CASE 2 & 0.485529 & 0.0783919 \\
CASE 3 & 0.849635 & 0.0702324 \\
CASE 4 & 0.923187 & 0.0854423 \\
CASE 5 & 0.669008 & 0.1395260 \\
CASE 6 & 0.548559 & 0.0939479 \\
CASE 7 & 0.888621 & 0.234654 \\
CASE 8 & 0.681491 & 0.133305 \\
CASE 9 & 0.503182 & 0.124024 \\
CASE 10 & 0.814612 & 0.169953 \\
CASE 11 & 0.771479 & 0.087438 \\
CASE 12 & 0.540923 & 0.175132 \\
CASE 13 & 0.546780 & 0.168501 \\
CASE 14 & 0.578624 & 0.137332 \\
CASE 15 & 0.558167 & 0.129357 \\
CASE 16 & 0.967700 & 0.206610 \\
CASE 17 & 0.553817 & 0.180807 \\
CASE 18 & 0.618631 & 0.255362 \\
CASE 20 & 0.876238 & 0.106067 \\
\hline
\end{tabular}


describes the dynamics of a global property (the general activation) of a complex system such as the human organism.

The confirmation, on the one hand, of a good fit between the real data and the theoretical curve, and on the other hand, of the homoscedasticity hypothesis, verifies Model (1). In other words, the deterministic time evolution of the extraversion variable $(G F P)$ measured by the Sensation-Seeking Scale, as a result of the effects of caffeine on a complex system such as the human organism, can be successfully described by Model (1), while variability, as represented by the residuals, is random in nature. Furthermore, the time patterns provided by Model (1) are the same as those described in other works for effects of stimulant drugs (e.g., caffeine) (Amigó et al., 2008a; Grossberg, 2000; Solomon \& Corbit, 1974).

For the control cases (participants who did not drink coffee but whose remaining conditions were the same as those in the experimental group), the corresponding plots of the experimental results of extraversion (GFP) (measured by the Sensation-Seeking Scale) over time are shown in Figures 21 to 25 . As a starting point, neither a statistically significant variability around the initial value $y_{0}$ nor a decreasing tendency (due to boredom) was expected, which is the case of control subjects 3, 4 and 5 (Figures 23, 24 and 25). With control 1 (Figure 21), the exceptions can be explained by this participant's special interest in the experiment, and also for control 2 (Figure 22) by the participant's intention to recover normality in the last part of the experiment.

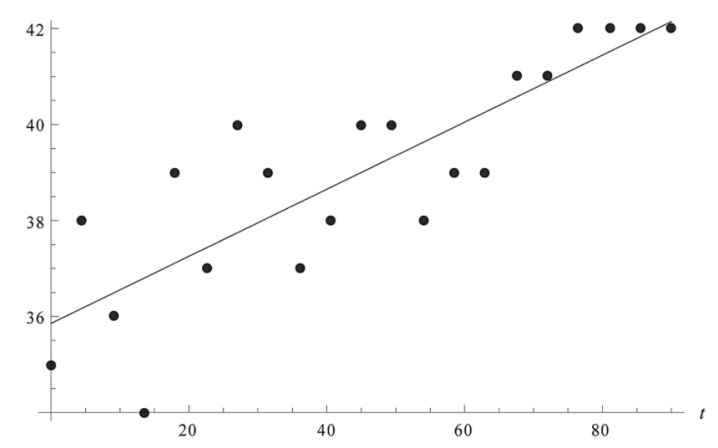

Figure 21: Control 1 (control group), real values $x(t)$ (dots) together with fitted time-pattern $y(t)$ (line) versus time $t$. $\left(R^{2}=0.660\right)$.

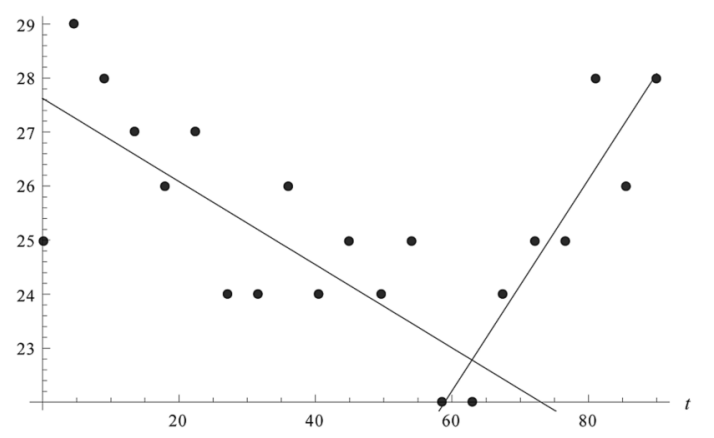

Figure 22: Control 2 (control group), real values $x(t)$ (dots) together with fitted time-pattern $y(t)$ (line) versus time $t$. $\left(R^{2}=0.221\right)$.

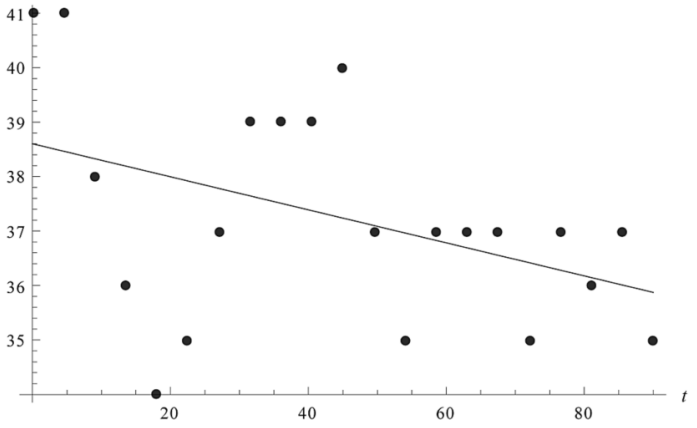

Figure 23: Control 3 (control group), real values $x(t)$ (dots) together with fitted time-pattern $y(t)$ (line) versus time $t .\left(R^{2}=0.099\right)$.

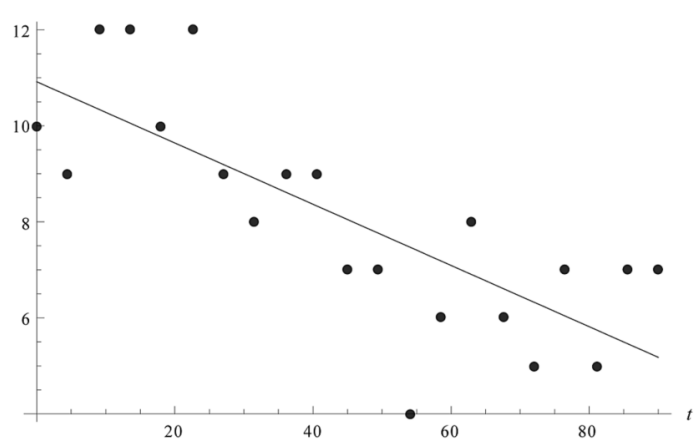

Figure 24: Control 4 (control group), real values $x(t)$ (dots) together with fitted time-pattern $y(t)$ (line) versus time $t$. $\left(R^{2}=0.587\right)$.

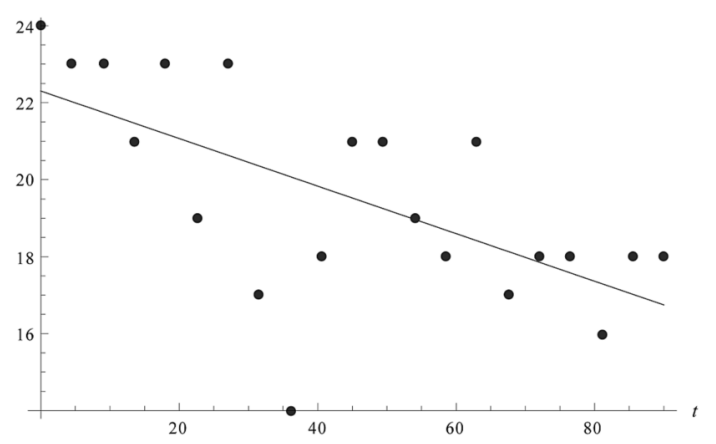

Figure 25: Control 5 (control group), real values $x(t)$ (dots) together with fitted time-pattern $y(t)$ (line) versus time $t .\left(R^{2}=0.332\right)$.

Other conclusions may be drawn from the analysis of the parameters values. The process of fitting Model (1) to the real extraversion values $(G F P)$ measured by the Sensation-Seeking Scale provides the individual values for the parameters corresponding to the twenty cases in the experimental group, which are shown in Table 3. The measurement units of the parameters are also provided in Table 1 . The initial extraversion value $(G F P), y_{0}$, is presented in Table 3 (despite its remaining invariable during the fitting process) for it to be compared with its tonic value, $b$.

One interesting conclusion drawn from Table 3 is the relationship between initial extraversion $(G F P)\left(y_{0}\right)$ and 
Table 3

Values of the model parameters for the twenty cases in the experimental group

\begin{tabular}{lcccccccc}
\hline & $y_{0}$ & $\tau$ & $\alpha$ & $\beta$ & $a$ & $b$ & $p$ \\
\hline CASE 1 & 11.0 & 40.50 & 0.0580 & 0.0380 & 1.265 & 12.65 & 5.00 & 0.000055 \\
CASE 2 & 27.0 & 45.00 & 0.0360 & 0.0200 & 1.000 & 31.05 & 2.10 & 0.000010 \\
CASE 3 & 28.0 & 47.50 & 0.0380 & 0.0190 & 1.365 & 28.00 & 2.20 & 0.000033 \\
CASE 4 & 26.0 & 57.00 & 0.0550 & 0.0230 & 0.935 & 28.60 & 3.30 & 0.000061 \\
CASE 5 & 26.0 & 47.50 & 0.0570 & 0.0440 & 1.210 & 22.10 & 3.20 & 0.000005 \\
CASE 6 & 40.0 & 25.00 & 0.0600 & 0.0115 & 1.265 & 32.00 & 1.40 & 0.000045 \\
CASE 7 & 25.0 & 60.00 & 0.0600 & 0.0400 & 1.400 & 5.750 & 1.65 & 0.000300 \\
CASE 8 & 33.0 & 70.00 & 0.0001 & 0.0400 & 0.300 & 35.00 & 63.0 & 0.002000 \\
CASE 9 & 35.0 & 21.25 & 0.0400 & 0.0600 & 1.155 & 31.00 & 2.50 & 0.000050 \\
CASE 10 & 38.0 & 45.00 & 0.0600 & 0.0400 & 1.100 & 35.00 & 1.30 & 0.000007 \\
CASE 11 & 29.0 & 33.25 & 0.0690 & 0.0460 & 1.320 & 37.00 & 4.20 & 0.000010 \\
CASE 12 & 25.0 & 54.00 & 0.0285 & 0.0440 & 1.045 & 15.20 & 2.20 & 0.000070 \\
CASE 13 & 30.0 & 84.00 & 0.0095 & 0.0180 & 1.155 & 32.00 & 2.90 & 0.000027 \\
CASE 14 & 32.0 & 15.00 & 0.1100 & 0.0210 & 1.210 & 29.00 & 1.00 & 0.000110 \\
CASE 15 & 36.0 & 61.75 & 0.0630 & 0.0350 & 1.140 & 24.00 & 4.00 & 0.000063 \\
CASE 16 & 19.0 & 27.00 & 0.0630 & 0.0380 & 1.155 & 8.400 & 3.15 & 0.000060 \\
CASE 17 & 23.0 & 31.50 & 0.0540 & 0.0440 & 1.380 & 31.50 & 1.30 & 0.000081 \\
CASE 18 & 20.0 & 63.00 & 0.0050 & 0.0130 & 1.155 & 13.50 & 5.20 & 0.002500 \\
CASE 19 & 26.0 & 38.00 & 0.0100 & 0.0300 & 1.100 & 24.00 & 7.00 & 0.000350 \\
CASE 20 & 22.0 & 30.00 & 0.0050 & 0.0600 & 1.100 & 20.00 & 25.0 & 0.001500 \\
\hline
\end{tabular}

tonic extraversion $(G F P)(b)$. Indeed, a positive correlation between them $(r=.67, p<.01)$ exists. Yet as the lists of adjectives were completed with participants on an empty stomach, and after the participants had awaken, this outcome statistically shows that tonic extraversion $(G F P)$ can be identified with its value for individuals under such conditions.

The importance of tonic extraversion $(G F P)$ must be remarked in the overall model context. In the work of Amigó et al. (2008a), the relationship between tonic extraversion $(G F P)$ and its phasic response (its change over time) was presented as a result of a stimulant drug intake (e.g., caffeine). The conclusion presented is that a lower tonic value produces a greater response, and vice versa. This greater response involves greater pleasure sensation owing to the excitation effect (the term in (1)), as well as greater craving sensation owing to the inhibitor effect (the term in (1)). Consequently, an extravert individual, characterized by low tonic extraversion $(G F P)$, is more prone to addiction than an introvert, characterized by a high value.

\section{Discussion}

The main objective of this paper centers on the theoretical and mathematical study of the short-term dynamic change of the General Factor of Personality (GFP) produced by ingesting a substance with a well-known stimulant effect, caffeine in this case. The effect of coffee is measured by the Sensation-Seeking Scale of the MAACL-R, related with the GFP, which is representative of the individual activation level whose biological basis, following the UPTT, is the general activation or extraversion (Amigó, 2005; Amigó et al., 2008a; Caselles et al., 2010). Extraversion is the physiological substrate of the GFP. This objective has been achieved with this study of twenty-five individual cases, five of which were control cases, and by offering them coffee (caffeine) as a stimulant drug. Thus, the results of this experiment prove that personality is dynamic in nature and varies as a result of a stimulant drug intake. On the one hand, personality is a trait (tonic or basal activation) because it remains constant while no stimulus is present and, on the other hand, it varies over time (phasic response) when a stimulus is produced in the individual, where the personality trait is a steady state of the model toward which all trajectories generally tend when the stimulus vanishes. Other conclusions have been drawn from the experiment: a relationship between personality, as a trait, and the effect of a single caffeine dose has been observed; personality (tonic or basal activation) is both a predictor and an involved factor in the effects that coffee has.

Alternatively, the $S S-T$ (Sensation-Seeking Trait) and the $S S$-S (Sensation-Seeking State) scores of the trait have been considered. The $S S-T$ has been considered in this paper and in others (Amigó et al., 2008a; Amigó et al., 2010; Caselles et al., 2010) to be a good approach to the GFP given its relationship with the general activation level. The $S S-T$ is the Sensation-Seeking Scale trait format from the $M A A C L-R$, while the $S S-S$ is the state format of the same 
scale. The score in these scales has been considered to be representative of the GFP. A good correlation between the $S S-T$ scale and the GFPQ has been found. Nonetheless, the greater the trait and differential scores $(S S-T$ and $S S$ $S$ ), the greater the detected phasic response to a caffeine dose (greater increase and longer duration measured with the $S S-S$ score). Specifically, the time changes noted in the state level suggest changes of personality as a result of one caffeine dose. Remember that a high score in the $S S-T$ implies a low level of tonic activation, and vice versa.

These outcomes are consistent with the UPTT. A high trait level means a low activation level in a weak stimulation situation (on an empty stomach in the morning). In addition, a high trait level means a more intensive phasic response (a higher peak) as a result of a stimulant substance intake. The higher the trait level in relation to the low stimulation level state, the higher the state level as a response to a stimulant; this is exactly the outcome obtained.

For Cases 1 to 20, which make up the experimental group, the determination coefficient (Table 2) shows values that represent a high degree of fit between the real data and Model (1) (see Figures 1 to 20 to visually observe this fit). These real data represent the effect of caffeine consumption. Moreover, the analysis of the residuals confirms, for each case, that they are distributed normally (Table 2), and that they depend on neither time nor the computed variable. In other words, high variability (see Figures 1 to 20 to visually observe this variability) is random in nature, i.e., it is not due to caffeine intake, but to other causes, e.g., the kind of data (responses to a questionnaire and a hedonic scale), and to natural differences among individuals. These conclusions verify Model (1); that is, the deterministic predictions of Model (1) are coherent to the experimental results.

In addition, a different time pattern is observed for the participants in the control group. Figures 21 to 25 show the experimental values and the corresponding fitting straight lines. Figures 26 to 30 illustrate the best way to fit the model to the control group individuals. Note the low $R^{2}$ values and the non random distribution of the data points around the fitted curves. The model cannot be well fitted to the data corresponding to these individuals. We should also consider that the response curves produced by the model are inverted $U$ shapes, perhaps with oscillations in the end part (the model is designed to represent the brain's reaction to a stimulus). Consequently, the model can only be well fitted to sets of data points that apparently represent portions of such a shape, and that are produced as the brain's reaction to a given stimulus.

The values of the model parameters for the participants in the experimental group are presented in Table 3. They have been obtained with a fitting program used for the situation. One conclusion drawn from analyzing this table is that there are no statistically significant differences between tonic extraversion $(G F P), b$, and initial extraversion

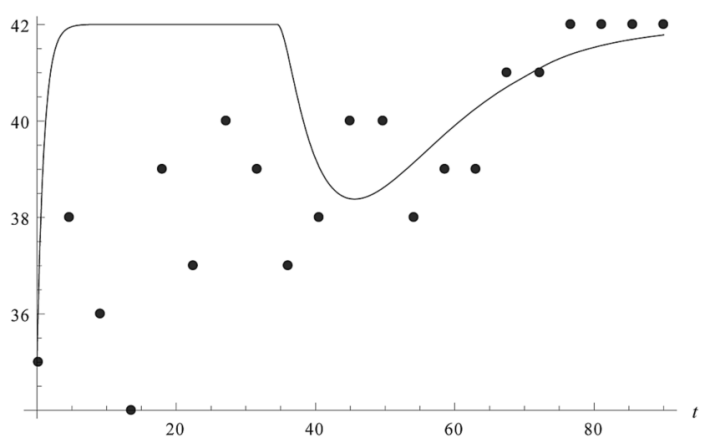

Figure 26: Control 1 (control group), real values $x(t)$ (dots) together with the best fitted model's time-pattern $y(t)$ (line) versus time $t$. $\left(R^{2}=0.008\right)$.

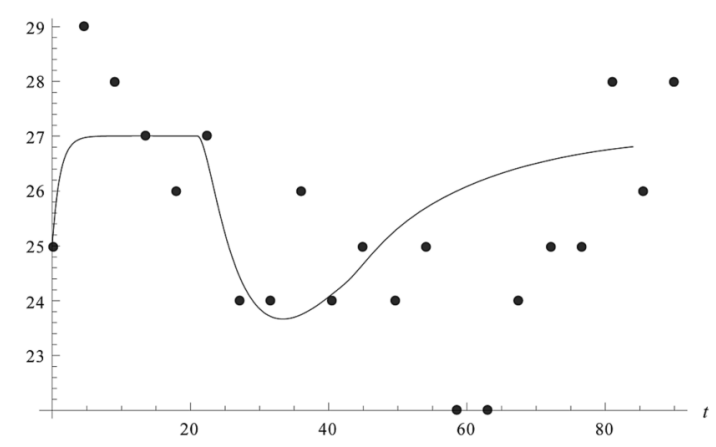

Figure 27: Control 2 (control group), real values $x(t)$ (dots) together with the best fitted model's time-pattern $y(t)$ (line) versus time $t$. $\left(R^{2}=0.221\right)$.

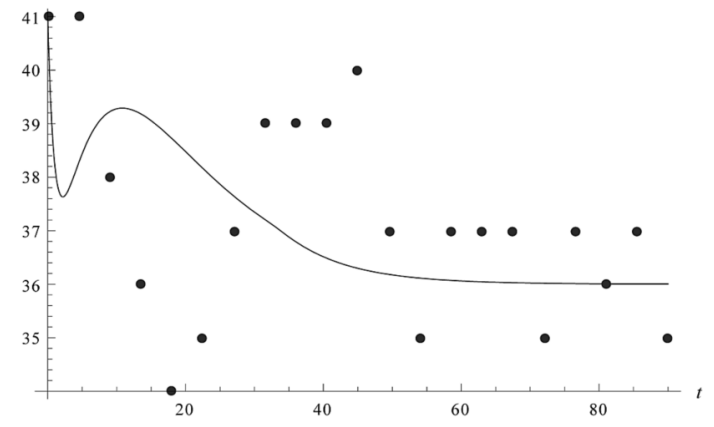

Figure 28: Control 3 (control group), real values $x(t)$ (dots) together with the best fitted model's time-pattern $y(t)$ (line) versus time $t .\left(R^{2}=0.001\right)$.

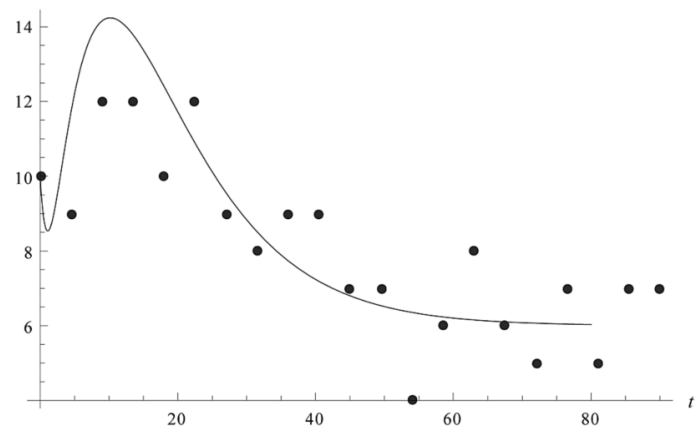

Figure 29: Control 4 (control group), real values $x(t)$ (dots) together with the best fitted model's time-pattern $y(t)$ (line) versus time $t$. $\left(R^{2}=0.734\right)$. 


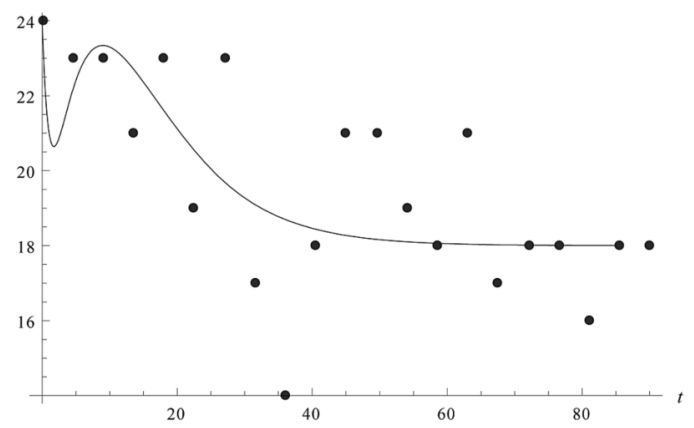

Figure 30: Control 5 (control group), real values $x(t)$ (dots) together with the best fitted model's time-pattern $y(t)$ (line) versus time $t$. $\left(R^{2}=0.403\right)$.

$(G F P), y_{0}$ (the extraversion value for individuals participating on an empty stomach in the morning, these being the participants' conditions before starting the experiment) $(r=.67 ; p<.01)$. So when the stimulus disappears, the subject recovers his or her rest state, unless another stimulus is applied.

A biological foundation of the observed effects is proposed and discussed below.

The prolonged duration of the caffeine effect means that this substance becomes a prolonged activator stimulus; that is, a stressor that maintains its effect over a lengthy period. Consequently, great activation of the stress system is expected. This activation would develop in two time phases governed by two different, but interrelated, stress response systems. The first stress system is activated when the stressor occurs and prepares the organism for action. It corresponds to a combination of the neural and neuroendocrine axes (axis I and axis II, respectively) (Everly, 1989 ), or to the locus ceruleus-norepinephrine ( $L C$ $N E$ )/autonomic (sympathetic) nervous system (Chrousos \& Gold, 1992), with great catecholaminergic activation in both cases. Following the same authors, the second stress system would correspond to axis III, or the endocrine axis (with a cortisol secretion), and to the $C R H$ (corticotropinreleasing hormone), or the hypothalamic-pituitary-adrenal (HPA) system, respectively. It represents a high activation level of inhibitory character. The second stress system is activated when the stressor is prolonged over a lengthy period or when it is very strong.

In addition, the UPTT states that the biological base of the GFP or extraversion is the stress system (Amigó, 2005; Amigó et al., 2008a). In this sense, the sensation-seeking trait is a good approach to the GFP or the general activation trait. An animal sensation-seeking model has proved that rats with a high response to stress situations, high responders $(H R)$ search through experiment stress unlike low responders $(L R)$, because the high concentrations of glucocorticoids reinforce their tendency (Piazza et al., 1993). Alternatively in humans, high sensation-seeking trait scores are associated with protective mechanisms against life stress, and they do not relate with psychopathology and, specifically, with neurotic disorders (De Brabander, Hellemans, Bone, \& Gerits, 1996; Farmer et al., 2001; Zuckerman \& Neeb, 1979).

As in the present study, the scored registers were prolonged only for 1.5 hours, the activation of the first stress system was that mainly observed. The hedonic tone is highly positive, mainly in the first half hour. The Sensation-Seeking Scale from the $M A A C L-R$ relates with the positive hedonic tone. Note that the Sensation-Seeking Scale, together with the positive affect, constitutes the PASS (Positive And Sensation-Seeking Affects), unlike the Anxiety, Depression and Hostility scales that contribute to the dysphoria factor (Zuckerman \& Lubin, 1985; Zuckerman, Lubin, \& Rinck, 1983).

The decreasing SS-S score tendency observed by 1.5 hours is expected to continue if the experiment is prolonged in time and the number of registers increases. We should consider that the peak plasma caffeine concentration is reached between 15 and 120 minutes after oral ingestion in humans (Arnaud \& Welsch, 1982; Bonati, Latini, Tognoni, Young, \& Garattini, 1984), and that caffeine half-lives range from 2.5 to 4.5 hours in humans for doses lower than 10 $\mathrm{mg} / \mathrm{kg}$ (Arnaud, 1987). The fact that this $S S-S$ score decreases in some cases below the baseline does not mean that the sensation-seeking dynamics ends. In contrast, it means that the second stress system activates with slower dynamics, an inhibitory character, and with a negative hedonic tone. Thus, the sensation-seeking dynamics would cause the activation of both the (activator and inhibitor) stress systems in consecutive time phases. However, this is a question that requires a longer experimental period which could be performed in a future time, but only if the experimental group is not sensitive to boredom. Bear in mind that a previous pilot study informed us that the participants showed evident signs of boredom after 1.5 hours which distorted the effects of coffee intake.

An alternative experimental design could be, for instance, filling in the registers every 15 minutes over a 4-hour period. The intercalation of other well chosen activities could prove interesting to avoid boredom. The disadvantage of this design is that the variations of personality would not be observed in the short term. Therefore, the presented experimental design is a relevant starting point to study rapid changes in personality dynamics.

For a future experiment, new personality scales could also be considered. If the GFP or extraversion is the higher trait of a personality hierarchy, then the observation of the dynamics of other personality factors, such as extraversion, neuroticism and psychoticism, will be interesting as they are considered subsystems of either the unique trait or the general activation trait (Amigó, 2005).

One limitation of this study is that an indirect measure of the GFP state format has been used. This indirect measure is the $S S-S$ (Sensation-Seeking in the state format). It has been proved that the GFP and sensation seeking are closely 
related, but they are not really the same trait of personality. In the future, it will be necessary to use a state format of the $G F P Q$ to directly measure the very short-term GFP.

Despite the need of new studies to obtain in-depth knowledge of personality dynamics and drug effects, the present study is a fundamental starting point to understand the dynamics of the general factor of personality through the experimental verification of a valuable mathematical model, and proposes a biological approach to describe it.

Regarding future studies on the possible practical utility of the method described herein, it is possible to consider "single-dose fitting" studies that permit the determination of an adequate dose of a given stimulant drug to obtain a desired response curve of the evolution of the activation effect in a given individual. Note that, as previously shown, the model is calibrated for a given individual and a given drug by observing the effects of a given drug dose in the forms filled by the individual, and that when the drug parameters and the individual's parameters are known, only dose and the resulting activation can vary.

\section{References}

Amigó, S. (2005). La teoría del rasgo único de personalidad. Hacia una teoría unificada del cerebro y la conducta [The Unique Personality Trait Theory. Towards a unified theory of brain and behavior]. Valencia, Spain: Universitat Politècnica de València

Amigó, S., Caselles, A., \& Micó, J. C. (2008a). A dynamic extraversion model: the brain's response to a single dose of a stimulant drug. British Journal of Mathematical and Statistical Psychology, 61, 211-231. doi:10.1348/000711007X185514

Amigó, S., Micó, J. C., \& Caselles, A. (December, 2008b). Adjective scale of the unique personality trait: measure of personality as an overall and complete system. Proceedings of the 7th Congress of the European Systems Union, Lisboa, Portugal.

Amigó, S., Micó, J. C., \& Caselles, A. (2009). Five adjectives to explain the whole personality: a brief scale of personality. Revista Internacional de Sistemas, 16, 41-43.

Amigó, S., Caselles, A., \& Micó, J. C. (2010). The General Factor of Personality Questionnaire (GFPQ): Only one factor to understand the personality? The Spanish Journal of Psychology, 13, 5-17.

Arnaud, M. J. (1987). The pharmacology of caffeine. Progress in Drug Research, 31, 273-313.

Arnaud, M. J., \& Welsch, C. (1982). Theophyline and caffeine metabolism in man. In N. Reitbrock, B. G. Woodcock, \& A. H. Staib (Eds.), Teophyline and Other Methylxanthines (pp. 135-148). Zurich, Switzerland: Friedrich Vieweg and Sons.

Bogaert, A. F., \& Rusthon, J. P. (1989). Sexuality, delinquency and $\mathrm{r} / \mathrm{K}$ reproductive strategies: Data from Canadian university sample. Personality and Individual Differences, 10, 10711077. doi:10.1016/0191-8869(89)90259-6
Bonati, M., Latini, R., Tognoni, G., Young, J. F., \& Garattini, S. (1984). Interspecies comparison of in vivo caffeine pharmacokinetics in man, monkey, rabbit, rat and mouse. Drug Metabolism Reviews, 15, 1355-1383. doi:10.3109/03602538409 029964

Caselles, A. (1998). REGINT: a tool for discovery by complex function fitting. In R. Trappl (Ed.), Cybernetics and Systems'98, Austrian Society for Cybernetic Studies, Vienna, 787-792.

Caselles, A., Micó, J. C., \& Amigó, S. (2010). Cocaine addiction and personality: A mathematical model. British Journal of Mathematical and Statistical Psychology, 63, 449-480. doi:10.1348/000711009X470768

Chrousos, G. P., \& Gold, P. W. (1992). The concepts of stress and stress system disorders. Journal of the American Medical Association, 267, 1244-1252. doi:10.1001/jama.1992. 034800 90092034

Childs, E., \& De Wit, H. (2006). Subjective, behavioral, and physiological effects of acute caffeine in light, nondependent caffeine users. Psychopharmacology, 185, 514-523. doi:10.1007/ s00213-006-0341-3

De Brabander, B., Hellemans, J., Bone, C., \& Gerits, P. (1996). Locus of control, sensation seeking, and stress. Psychological Reports, 79, 1307-1312.

Draper, N. R., \& Smith, H., (1981). Applied Regression Analysis (2nd Ed.) (pp. 141-192). New York, NY: John Wiley \& Sons

Erdle, S., Irwing, P., Rushton, J. P., \& Park, J. (2010). The general factor of personality and its relation to self-esteem in 628,640 Internet respondents. Personality and Individual Differences, 48, 343-346. doi:10.1016/j.paid.2009.09.004

Everly, G. S. (1989). A clinical guide to the treatment of the human stress response. New York, NY: Plenum Press.

Eysenck, H. J. (1967). The biological basis of personality. Springfield, IL: Thomas.

Farmer, A., Redman, K., Harris, T., Mahmood, A., Sadler, S. \& McGuffin, P. (2001). Sensation-seeking, life events and depression: The Cardiff depression Study. British Journal of Psychiatry, 178, 549-552. doi:10.1192/bjp.178.6.549

Figueredo, A. J., Vásquez, G., Brumbach, B. H., Schneider, S. M. R., Sefcek, J. A., Tal, I. R.,... Jacobs, W. J. (2006). Consilience and Life History Theory: From genes to brain to reproductive strategy. Developmental Review, 2, 243-275. doi:10.1016/j.dr.2006.02.002

Figueredo, A. J., \& Rushton, J. P. (2009). Evidence for shared genetic dominance between the general factor of personality, mental and physical health, and life history traits. Twin Research and Human Genetics, 12, 555-563. doi:10.1375/twin.12.6.555

Garrett, B. E., \& Griffiths, R. R. (1998). Physical dependence increases the relative reinforcing effects of caffeine versus placebo. Psychopharmacology, 139, 195-202. doi:10.1007/ s002130050704

Grossberg, S. (2000). The imbalanced brain: from normal behavior to schizophrenia. Biological Psychiatry, 48, 81-98. doi:10.1016/S0006-3223(00)00903-3

Haskell, C. F., Kennedy, D. O., Wesnes, K. A., \& Scholey, A. B. (2005). Cognitive and mood improvements of caffeine in 
habitual consumers and habitual non-consumers of caffeine. Psychopharmacology, 179, 813-825. doi:10.1007/s00213-0042104-3

James, J. E. (1994). Does caffeine enhance or merely restore degraded psychomotor performance? Neuropsychobiology, 3, 124-125.

Lieberman, H. R., Wurtman, R. J., Emde, G. G., Roberts, C., \& Coviella, I. L. (1987). The effects of low doses of caffeine on human performance and mood. Psychopharmacology, 92, 308-312. doi:10.1007/BF00210835

Lubin, G., Van Whitlock, R., Reddy, D., \& Petren, S. (2001). A comparison of the short and long forms of the Multiple Affect Adjective Check List-Revised (MAACL-R). Journal of Clinical Psychology, 57, 411-416. doi:10.1002/jclp.1023

Mackay, M., Tiplady, B., \& Scholey, A.B. (2002). Interactions between alcohol and caffeine in relation to psychomotor speed and accuracy. Human Psychopharmacology: Clinical and Experimental, 17, 151-156. doi:10.1002/hup.371

McNair, D. L. M., \& Droppleman, L. (1971). Profile of mood states. San Diego, CA: Educational and Industrial Testing Service.

Mitchell, S. H., De Wit, H., \& Zacny, J. P. (1995). Caffeine withdrawal symptoms and self administration following caffeine deprivation. Pharmacology, Biochemistry \& Behavior, 51, 941-945. doi:10.1016/0091-3057(94)00426-J

Musek, J. (2007). A general factor of personality: Evidence for the Big One in the five-factor model. Journal of Research in Personality, 41, 1213-1233. doi:10.1016/j.jrp.2007.02.003

Nehlig, A. (1999). Are we dependent upon coffee and caffeine? A review on human and animal data. Neuroscience \& Biobehavioral Reviews, 23, 563-576. doi:10.1016/S01497634(98)00050-5

Nurminen, M. L., Niittynen, L., Korpela, R., \& Vapaatalo, H. (1999). Coffee, caffeine and blood pressure: a critical review. European Journal of Clinical Nutrition, 53, 831-839. doi:10.1038/ sj.ejcn.1600899

Pelechano, V. (1973). Personalidad y adaptación: tres escuelas y un modelo. Barcelona, Spain: Vicens Vives.

Pelechano, V. (2000). Psicología sistemática de la personalidad. Barcelona, Spain: Ariel.

Pickering, A. D. (2004). The Neuropsychology of Impulsive Antisocial Sensation Seeking Personality Traits: From dopamine to hippocampal function? In R. M. Stelmack (Ed.), On the Psychobiology of Personality. New York, NY: Elsevier Ldt.

Pickering, A. D., \& Smille, L. D. (2008). The behavioral activation system: challenges and opportunities. In P. J. Corr (Ed.), The Reinforcement Sensitivity Theory of Personality. New York, NY: Cambrige University Press.

Piazza, P. V., Deroche, V., Deminière, J. M., Maccari, S., Le Moal, M., \& Simon, H. (1993). Corticosterone in the range of stressinduced levels possesses reinforcing properties: Implications for sensation-seeking behaviors. Proceedings of the National Academy of Sciences, 90, 11738-11742. doi:10.1073/pnas.90.24.11738

Revelle, W., Humphreys, M. S., Simon, L., \& Gilliland, K. (1980). The interactive effect of personality, time of the day and caffeine: a test of the arousal model. Journal of Experimental Psychology: General, 109, 1-31. doi:10.1037//00963445.109.1.1

Reyner, L. A., \& Horne, J. A. (2000). Early morning driver sleepiness: effectiveness of $200 \mathrm{mg}$ of caffeine. Psychopharmacology, 37, 251-256.

Roberts, H. R., \& Barone, J. J. (1983). Biological effects of caffeine: history and use. Food Technology, 37, 32-39.

Rogers, P. J., \& Dernoncourt, C. (1998). Regular caffeine consumption: a balance of adverse and beneficial effects for mood and psychomotor performance. Pharmacology Biochemistry \& Behavior, 59, 1039-1045. doi:10.1016/S00913057(97)00515-7

Rogers, P. J., Martín, J., Smith, C., Heatherley, S. V., \& Smit, H. J. (2003). Absence of reinforcing mood and psychomotor performance effects of caffeine in habitual non-consumers of caffeine. Psychopharmacology, 167, 54-62.

Rushton, J. P., Bons, T. A., \& Hur, Y-M. (2008). The genetics and evolution of the general factor of personality. Journal of Research in Personality, 42, 1173-1185. doi:10.1016/j.jrp. 2009.01.005

Rushton, J. P., Bons, T. A., Ando, J., Hur, Y-M., Irwing, P., Vernon, P.A.,... Barbaranelli, C. (2009). A general factor of personality from multitrait-multimethod data and cross-national twins. Twin Research and Human Genetics, 12, 356-365. doi:10.1375/ twin. 12.4.356

Rushton, J. P., \& Irwing, P. (2008). A General Factor of Personality (GFP) from two meta-analyses of the Big Five: Digman (1997) and Mount, Barrik, Scullen, and Rounds (2005). Personality and Individual Differences, 45, 679-683. doi:10.1016/j.paid. 2008.07.015

Rushton, J. P., \& Irwing, P. (2009a). A general factor of personality in the Comrey Personality Scales, the Minnesota Multiphasic Personality Inventory-2, and the Multicultural Personality Questionnaire. Personality and Individual Differences, 46, 437-442. doi:10.1016/j.paid.2008.11.015

Rushton, J. P., \& Irwing, P. (2009b). A general factor of personality in 16 sets of the Big Five, the Guilford-Zimmerman Temperament Survey, the California Psychological Inventory, and the Temperament and Character Inventory. Personality and Individual Differences, 47, 558-564. doi:10.1016/j.paid. 2009.05.009

Rushton, J. P., \& Irwing, P. (2009c). A general factor of personality (GFP) from the Multidimensional Personality Questionnaire. Personality and Individual Differences, 47, 571-576. doi:10.1016/ j.paid.2009.05.011

Rushton, J. P., \& Irwing, P. (2009d). A General Factor of Personality in the Millon Clinical Multiaxial Inventory-III, the Dimensional Assessment of Personality Pathology, and the Personality Assessment Inventory. Journal of Research in Personality, 43, 1091-1095. doi:10.1016/j.jrp.2009.06.002

Schermer, J. A., \& Vernon, P. A. (2010). The correlation between general intelligence (g), a general factor of personality (GFP), and social desirability. Personality and Individual Differences, 48, 187-189. doi:10.1016/j.paid.2009.10.003 
Schutte, N. S., Malouff, J. M., Segrera, E., Wolf, A., \& Rodgers, L. (2003). States reflecting the Big Five dimensions. Personality and Individual Differences, 34, 591-603. doi:10.1016/S01918869(02)00031-4

Silverman, K., \& Griffiths, R. R. (1992). Low-dose caffeine discrimination and self-reported mood effects in normal volunteers. Journal of the Experimental Analysis of Behavior, 57, 91-107. doi:10.1901/jeab.1992.57-91

Smit, H. J., \& Rogers, P. J. (2000). Effects of low doses of caffeine on cognitive performance, mood and thirst in low and higher caffeine consumers. Psychopharmacology, 152, 167-173. doi: $10.1007 / \mathrm{s} 002130000506$

Smith, B. D. (1983). Extraversion and electrodermal activity: arousability and the inverted-U. Personality and Individual Differences, 4, 411-420. doi:10.1016/0191-8869(83)90007-7

Smith, A., Brice, C., Nash, J., Rich, N., \& Nutt, D. J. (2003). Caffeine and central noradrenalin: effects on mood, cognitive performance, eye movements and cardiovascular function. Journal of Psychopharmacology, 17, 283-292. doi:10.1177/026988 11030173010

Solomon, R. L., \& Corbit, J. D. (1974). An opponent-process theory of motivation. I. Temporal dynamics of affect. Psychological Review, 81, 119-145. doi:10.1037/h0036128

Swift, C. G., \& Tiplady, B. (1988). The effects of age on the response to caffeine. Psychopharmacology, 94, 29-31. doi:10.1007/BF00735876

Tinley, E. M., Durlach, P. J., \& Yeomans, M. R, (2004). How habitual caffeine consumption and dose influence flavour preference conditioning with caffeine. Physiology \& Behavior, 82, 317-324. doi:10.1016/j.physbeh.2004.03.018

Veselka, L., Schermer, J. A., Petrides, K. V., Cherkas, L. F., Spence, T. D., \& Vernon, P.A. (2009a). A general factor of personality: Evidence from the HEXACO Model and a measure of trait emotional intelligence. Twin Research and Human Genetics, 12, 420-424. doi:10.1375/twin.12.5.420

Veselka, L., Schermer, J. A., Petrides, K. V., \& Vernon, P. A. (2009b). Evidence for a heritable general factor of personality in two studies. Twin Research and Human Genetics, 12, 254260. doi:10.1375/twin.12.3.254
Warburton, D. M., Bersellini, E., \& Sweeney, E. (2001). An evaluation of a caffeinated tauring drink on mood, memory and information processing in healthy volunteers without caffeine abstinence. Psychopharmacology, 158, 322-328.

Wilson, G. A. (1990). Personality, time of day, and arousal. Personality and Individual Differences, 11, 153-168. doi:10.1016/0191-8869(90)90008-F

Yeomans, M. R., Javaherian, S., Tovey, H. M., \& Stafford, L. D. (2005). Attention bias for caffeine-related stimuli in high but not moderate or non-caffeine consumers. Psychopharmacology, 181, 477-485. doi:10.1007/s00213-005-0004-9

Yeomans, M. R., Spetch, H., \& Rogers, P. J. (1998). Conditioned flavour preference negatively reinforced by caffeine in human volunteers. Psychopharmacology, 137, 401-409. doi:10.1007/ s002130050636

Zuckerman, M., \& Lubin, B. (1985). The Multiple Affect Adjective Check List Revised. San Diego, CA: Educational and Industrial Testing Services.

Zuckerman, M., \& Neeb, M. (1979). Sensation seeking and psychopathology. Psychiatry Research, 1, 255-264. doi:10.1016/0165-1781(79)90007-6

Zuckerman, M. (1992). What is a basic factor and which factors are basic? Turtles all the way down. Personality and Individual Differences, 13, 675-681. doi:10.1016/0191-8869(92)90238$\mathrm{K}$

Zuckerman, M., Lubin, B., \& Rinck, C. M. (1983). Construction of new scales for the Multiple Affect Adjective Check List. Journal of Psychopathology and Behavioral Assessment, 5, 119-129. doi:10.1007/BF01321444

Zuckerman, M., Kuhlman, D. M., Joireman, J., Teta, P., \& Kraft, M. (1993). A comparison of three structural models for personality: The Big Three, The Big Five, and the Alternative Five. Journal of Personality and Social Psychology, 65, 757768. doi:10.1037/0022-3514.65.4.757

Received January 21, 2010 Revision received September 11, 2010 Accepted October 7, 2010 